medRxiv preprint doi: $h t$ tps://doi.org/10.1101/2022.02.23.22271386; this version posted February 24, 2022. The copyright holder for this preprint (which was not certified by peer review) is the author/funder, who has granted medRxiv a license to display the preprint in It is made available perpetuity

perpetuity.
a CC-BY-ND 4.0 International license.

\title{
Association of Physical Activity Volume and Intensity with Incident Cardiovascular Disease: a UK Biobank Study
}

\author{
Article Type: Original Paper
}

Authors and Affiliations: Paddy C. Dempsey ${ }^{1 \#, 2,3,4}$, *Alex V. Rowlands ${ }^{1,4}$, *Tessa Strain², Francesco Zaccardi ${ }^{1,5}$, Nathan Dawkins ${ }^{1,6}$, Cameron Razieh ${ }^{1,4,5}$, Melanie J. Davies ${ }^{1,4}$, Kamlesh K. Khunti ${ }^{1,5}$, Charlotte L. Edwardson ${ }^{1,4}$, *Katrien Wijndaele ${ }^{2}$, *Soren Brage ${ }^{2}$, *Tom Yates $^{1,4}$

\footnotetext{
${ }^{1}$ Diabetes Research Centre, College of Life Sciences, University of Leicester, Leicester, UK.

${ }^{2}$ MRC Epidemiology Unit, Institute of Metabolic Science, University of Cambridge, Cambridge

Biomedical Campus, Cambridge, UK.

${ }^{3}$ Baker Heart and Diabetes Institute, Melbourne, Australia.

${ }^{4}$ NIHR Leicester Biomedical Research Centre, Leicester, United Kingdom.

${ }^{5}$ Leicester Real World Evidence Unit, Diabetes Research Centre, University of Leicester, Leicester, UK

${ }^{6}$ School of Social and Health Sciences, Leeds Trinity University, Leeds, UK.
}

*Formed the core working group along with the first author, and contributed equally to the work \#Author and address for correspondence: Paddy C. Dempsey (paddy.dempsey@mrcepid.cam.ac.uk)

Main text word count $=3665$; Number of Tables $=3$; Number of Figures $=3$; Number of Supplementary Tables $=2$; Number of Supplementary Figures $=5$; Number of references $=$ 48

Keywords: physical activity; exercise; intensity; volume; accelerometer; cardiovascular disease; mortality 
medRxiv preprint doi: https://doi.org/10.1101/2022.02.23.22271386; this version posted February 24, 2022. The copyright holder for this preprint (which was not certified by peer review) is the author/funder, who has granted medRxiv a license to display the preprint in It is made available under a CC-BY-ND 4.0 International license.

\section{ABSTRACT}

Background: Although the cardiovascular disease (CVD) benefits of both overall volume and intensity of physical activity (PA) are known, the role of PA intensity, over and above volume, is poorly understood. We aimed to investigate the interplay between PA volume and intensity in relation to incident CVD.

Methods: Data were from 88,412 UK Biobank participants without prevalent CVD (58\% women) who wore an accelerometer on their dominant wrist for 7 days, from which we estimated total physical activity energy expenditure (PAEE) using population-specific validation. Cox proportional hazards regressions modelled associations between PAEE ( $\mathrm{kJ} / \mathrm{kg} /$ day)] and PA intensity [\%MVPA; the fraction of PAEE accumulated from moderate-tovigorous-intensity PA] with incident CVD, adjusted for potential confounders.

Results: There were 4,068 CVD events during 584,568 person-years of follow-up (median 6.8 years). Higher PAEE and higher \%MVPA (adjusted for PAEE) were associated with lower rates of incident CVD. In interaction analyses, CVD rates were 17\% (95\% Cl: 8-26\%) lower when MVPA accounted for $20 \%$ rather than $10 \%$ of $15 \mathrm{~kJ} / \mathrm{kg} / \mathrm{d}$ PAEE; equivalent to the difference between a 12-min stroll into a brisk 7-min walk. CVD rates did not differ significantly between values of PAEE when the \%MVPA was fixed at $10 \%$. However, the combination of higher PAEE and \%MVPA was associated with lower CVD rates. Rates were 24\% (10-35\%) lower for $20 \mathrm{~kJ} / \mathrm{kg} / \mathrm{d}$ PAEE with 20\% from MVPA, and 49\% (23-66\%) lower for $30 \mathrm{~kJ} / \mathrm{kg} / \mathrm{d}$ with $40 \%$ from MVPA (compared to $15 \mathrm{~kJ} / \mathrm{kg} / \mathrm{d}$ PAEE with $10 \%$ MVPA).

Conclusions: Reductions in CVD risk may be achievable through higher levels of PA volume and intensity, with the role of moderately intense PA appearing particularly important for future CVD risk. Our findings support multiple approaches or strategies to PA participation, some of which may be more practical or appealing to different individuals. 
medRxiv preprint doi: https://doi.org/10.1101/2022.02.23.22271386; this version posted February 24, 2022. The copyright holder for this preprint (which was not certified by peer review) is the author/funder, who has granted medRxiv a license to display the preprint in It is made available under a CC-BY-ND 4.0 International license .

\section{INTRODUCTION}

Regular physical activity (PA), particularly moderate-to-vigorous intensity physical activity (MVPA), is associated with a myriad of health benefits, including lower risk of cardiovascular disease (CVD), cancer, and all-cause mortality (1-3). However, epidemiological evidence used to inform current PA guidelines has relied mostly on self-reported measures of leisuretime or aerobic MVPA, which comprise only a very small proportion of the day and are prone to recall bias and measurement error $(4,5)$. In contrast, device-based measures of PA can more accurately capture sporadic activity of different intensities throughout the whole waking day, including light-intensity PA (an important contributor to total PA volume (6)), which could enable more specific and targeted PA recommendations.

Several cohort studies are now starting to report findings on the associations between device-based measures of PA with all-cause mortality (7-11), but few have examined associations with incident CVD (12-15). An important recent development has been the ability to process device-based measures of PA to understand the importance of volume and intensity as determinants of disease risk. Elucidating this relationship can be challenging, since PA volume is the product of intensity and time, thus volume and intensity are intrinsically linked. Nevertheless, they represent separate constructs and when used together, can capture different behavioural profiles $(16,17)$. For example, a person may achieve the same PA volume via a large amount of light-intensity PA (e.g. "pottering about"), or through short periods of higher intensity PA interspersed with high quantities of sedentary time (e.g. "an exerciser" or "active commuter").

A recent study highlighted the importance of this volume/intensity interaction for all-cause mortality, where a reduced risk was associated with higher volumes of PA, and with higher proportions of a given volume undertaken at a moderate-to-vigorous intensity (7). However, the interplay between volume and intensity has not been clearly elucidated in terms of risk for CVD, with previous studies only reporting associations related to time spent in MVPA or VPA $(13,15)$. There are supporting mechanisms suggesting that PA intensity may play a specific role in CVD risk, over and above volume, potentially due to greater stimulation and adaptation of cardiorespiratory-related pathways (18-22). Therefore, the interplay between PA volume and intensity warrants further investigation in association with CVD outcomes. Here, we investigate how device-based estimates of PA volume and different PA intensity profiles are associated with incident CVD in UK Biobank, the largest study of accelerometermeasured PA to date.

\section{METHODS}

\section{Data source and study population}


medRxiv preprint doi: https://doi.org/10.1101/2022.02.23.22271386; this version posted February 24, 2022. The copyright holder for this preprint (which was not certified by peer review) is the author/funder, who has granted medRxiv a license to display the preprint in It is made available under a CC-BY-ND 4.0 International license .

We used data from UK Biobank (application \#33266), a population-based prospective cohort study of over 500,000 adults aged 40-69 years, recruited between 2006 to 2010 from across the UK. Methods have been described in detail previously (23). In brief, a sub-sample of 103,686 participants responded to an email for the accelerometer sub-study between June 2013 and December 2015, with PA measurement a median of 5.3 years after their recruitment into the main study (24). The UK Biobank study received ethical approval from the Northwest England Research Ethics Committee (reference 16/NW/0274). Participants gave informed consent before participation.

\section{Physical activity volume and intensity derived from wrist acceleration}

Accelerometry subsample participants were asked to wear a triaxial accelerometer (AX3, Axivity, UK) on their dominant wrist continuously ( $24 \mathrm{~h} /$ day) for seven consecutive days. Measured acceleration was calibrated to local gravity (25) and the movement-related acceleration component isolated from noise and gravity and expressed as the Euclidian Norm Minus One (ENMO) metric (26). Non-wear was quantified as time periods of $\geq 60$ min where the standard deviation of acceleration in each of the three axes was $<13 \mathrm{mg}$, which was taken into consideration to minimise diurnal bias when summarising the 5-s epoch timeseries to average movement volume and distribution of intensity $(25,26)$. The average ENMO over 5-s epochs (the intensity time-series) was summarized into average proportions of daily time spent at different movement intensity levels (24). We estimated instantaneous PAEE from wrist movement intensity (27), the time integral of which constitutes total volume of activity as PAEE, as validated against the gold-standard criterion of doubly-labelled water (28) (Table S1). Participants were excluded if their accelerometer record failed calibration (including those not calibrated on their own data), had $<3$ days of valid wear (defined as $>16$ $\mathrm{h} /$ day), or wear data were not present for each 15-min period of the 24-h cycle (Figure S1). We focussed on two key metrics (Table S1) to summarize total PA volume and intensity, respectively:

- Average daily PAEE $(\mathrm{kJ} / \mathrm{kg} /$ day $)$ - calculated as the sum of activity-based energy expenditure from all intensity levels.

- Fraction of PAEE from MVPA (\%MVPA) - calculated as the sum of energy expenditure from any activity above $125 \mathrm{mg}$ (equivalent to 3 METs) divided by total PAEE.

\section{Covariate measurement}

All participants completed a touchscreen questionnaire and anthropometric assessment at recruitment into the main study, and some participants took part in up to two further touchscreen interviews. Since the accelerometry time-point was used as the analytical baseline for this study, covariate data from the interview undertaken closest to the 
medRxiv preprint doi: https://doi.org/10.1101/2022.02.23.22271386; this version posted February 24, 2022. The copyright holder for this preprint (which was not certified by peer review) is the author/funder, who has granted medRxiv a license to display the preprint in It is made available under a CC-BY-ND 4.0 International license.

accelerometry were used (7). Exceptions were: sex and Townsend Index of deprivation (based on postcode) that were only obtained at baseline; ethnicity (assumed not to have changed); and family medical history where a condition was counted if it was reported at any measurement point.

Covariates for this analysis included demographic and lifestyle related characteristics of age, sex, ethnicity (white/non-white), Townsend Index of deprivation, highest educational level achieved (degree or above/any other qualification/no qualification), employment status (unemployed/in paid or self-employment), parental history of CVD or cancer, season of accelerometry wear (using two orthogonal sine functions), alcohol drinking status (never/previous/current), salt added to food (never/sometimes), oily fish intake (never/sometimes), fruit and vegetable intake (a score from 0-4 taking into account questions on cooked and raw vegetables, fresh and dried fruit consumption), processed and red meat intake (average weekly frequency in days per week), and sleep duration $(<7,7-8$, $>8 \mathrm{~h}$ ), and a diagnosis of cancer prior to baseline. Prevalent CVD and cancer variables were derived from the self-reported history of heart attack, angina, stroke, or cancer variables, and from hospital episode data (corresponding ICD-10 codes for CVD or cancer I20-25, 160-69, or C00-99; and ICD-9 codes 410-414, 430-439, or 140-199, 201-208, 209.1-209.3, 209.7209.9). Health-related covariates included blood pressure and cholesterol medications, an insulin prescription or a self-report of doctor diagnosed diabetes, mobility limitations (selfreported longstanding illness or disability or chest pain at rest), and body mass index (BMI) in three categories $\left(<25,25-30, \geq 30 \mathrm{~kg} / \mathrm{m}^{2}\right)$.

\section{Ascertainment of incident CVD}

Incident non-fatal/fatal CVD was defined as the first appearance of ischaemic heart disease (ICD-10/9 codes I20-25/410-414) or cerebrovascular disease (ICD-10/9 codes 160-69/430438.9), identified from linkages to Hospital Episode Statistics (HES) or the national death index. Participants who did not experience a cardiovascular disease outcome were censored at death or the end of the study period, as appropriate (England 30/09/2021; Wales 28/02/2018; Scotland 31/07/2021).

\section{Statistical analyses}

All analyses were conducted using Stata v15.1 (StataCorp, TX, USA) and statistical significance was set at $p<0.05$ (two-tailed); results are reported with $95 \%$ confidence interval (CI). Participants with CVD prior to accelerometer wear were excluded. We also excluded those who had a CVD event ( $n=564)$ within the first year of follow-up, to reduce the risk of reverse causality bias. Using Cox proportional hazard regression models, we first investigated the associations of PAEE and fraction of PAEE from MVPA (the latter adjusted for PAEE) with incident CVD. These models used age as the underlying timescale, and 
medRxiv preprint doi: https://doi.org/10.1101/2022.02.23.22271386; this version posted February 24, 2022. The copyright holder for this preprint (which was not certified by peer review) is the author/funder, who has granted medRxiv a license to display the preprint in

It is made available under a CC-BY-ND 4.0 International license .

modelled exposures using cubic splines with three evenly-spaced knots. Exposure reference values were chosen as the nearest $5 \mathrm{~kJ} / \mathrm{kg} /$ day or $5 \%$ to the first percentile of the distribution among those who had a CVD event.

Directed acyclic graphs were used to visualise causal assumptions and guide which covariates to include in analyses, and at which level, a priori (29). We divided the covariates into two groups based on their likelihood of being on the causal pathway between PA and incident CVD (see Figure S2). As per STROBE recommendations, Model 0 adjusted for sex, with age as the underlying time scale. Model 1 was the main confounder-adjusted model and further included demographic and lifestyle covariates (sex, ethnicity, education level, employment status, Townsend index of deprivation, season of accelerometer wear, dietary variables, alcohol intake, smoking status, average sleep duration, and parental history of cardiovascular disease or cancer) and prevalent cancer. Model 2 additionally adjusted for health-related variables thought to be on the causal pathway, including blood pressure or cholesterol medication use, diabetes diagnosis or insulin prescription, body mass index, and mobility limitation. We used multiple imputation by chained equations ( 5 imputed datasets) for individuals with missing covariates. All covariates were included in the imputation model as well as the Nelson-Aalen estimate of cumulative baseline hazard of CVD and the incident CVD variable (30).

Interactions between PA volume and intensity were investigated by fitting a spline regression for PAEE and log-transformed \%PAEE from MVPA, including interaction terms between the four orthogonal spline variables and \%PAEE from MVPA. Using the coefficients, we plotted the fitted spline functions showing the association between PAEE and CVD risk for incremental fractions of PAEE from MVPA (10, 20, 30 and 40\%). A $15 \mathrm{~kJ} / \mathrm{kg} /$ day and $10 \%$ PAEE from MVPA reference was chosen for these models. Due to known differences in activity levels by sex in this cohort (24), interaction analyses were also sex-stratified to investigate integrated volume/intensity associations for women and men separately.

\section{Sensitivity analyses}

Several additional sensitivity analyses were performed, adjusting for covariates in Model 1. To further investigate potential reverse causality bias, we excluded those who had a CVD event/death within 2 years of follow-up or with prevalent cancer at baseline. We also investigated whether results differed when performing complete-case analysis (i.e. without imputation of missing covariate data). Finally, to assess whether the derived measures of PAEE and \%PAEE from MVPA used in this analysis provided a similar dose-response association with CVD incidence as more direct measures of PA using acceleration only, we repeated analyses using alternative exposure definitions of PA volume (average ENMO in $\mathrm{mg}$ ) and intensity (intensity gradient; a unitless integrated measure which describes the 
medRxiv preprint doi: https://doi.org/10.1101/2022.02.23.22271386; this version posted February 24, 2022. The copyright holder for this preprint (which was not certified by peer review) is the author/funder, who has granted medRxiv a license to display the preprint in

It is made available under a CC-BY-ND 4.0 International license.

negative curvilinear relationship between PA intensity and the time accumulated at that intensity (17)). As mentioned, Table S1 provides an overview and more detailed description of all the PA metrics used and the methods to calculate them. The relationships between the different PA volume and intensity metrics are also displayed in Figure S3.

\section{RESULTS}

\section{Descriptive characteristics}

Descriptive characteristics of the 88,412 participants at baseline are shown in Table 1 by incident CVD event and sex. Mean age was 62 (SD, 8) years; mean BMI was 26.6 (SD, 4.5) $\mathrm{kg} / \mathrm{m}^{2}$; and $58 \%$ were women. The age range was similar across sexes, but a higher proportion of women had a BMl in the normal range, had never smoked, took medications, or reported markers of poor health. Activity profiles between sexes were similar on average, but men had slightly lower overall PA volume and spent more time in higher intensity activities. During a median of 6.8 (IQR: 6.2-7.3) years (584,568 person-years) of follow-up, 4,068 CVD events occurred.

\section{Associations of PA volume and intensity}

Adjusted for potential confounders and prevalent cancer (model 1), both higher PAEE and \%PAEE from MVPA (adjusted for PAEE) were inversely associated with rates of incident CVD (Figure 1; Table 2). Compared to $15 \mathrm{~kJ} / \mathrm{kg} / \mathrm{d}$, a PAEE of $20 \mathrm{~kJ} / \mathrm{kg} / \mathrm{d}$ was associated with 16\% (95\% Cl: 8-23\%) lower rates. PAEE values of 30,40 , and $50 \mathrm{~kJ} / \mathrm{kg} / \mathrm{d}$ were associated with 35\% (21-46\%), 41\% (30-51\%), and 47\% (37-56\%) lower rates, respectively. Compared to accruing $10 \%$ of PAEE from MVPA, accruing $20 \%$ was associated with $26 \%(17-35 \%)$ lower rates. Accruing $30 \%, 40 \%$, and $50 \%$ of PAEE from MVPA were associated with $40 \%$ (31-48\%), 48\% (39-56\%), and 53\% (43-61\%) lower rates, respectively. Additional adjustment for covariates potentially on the causal pathway (model 2) attenuated all associations slightly.

\section{Interaction between PA volume and intensity}

In joint volume-intensity analyses, CVD rates were 17\% (8-26\%) lower when MVPA accounted for $20 \%$ rather than $10 \%$ of a fixed volume level of $15 \mathrm{~kJ} / \mathrm{kg} / \mathrm{d}$ PAEE (Figure 2; Table 3). CVD rates did not differ significantly with higher values of PAEE when the \%PAEE from MVPA was fixed; however, the combination of higher PAEE and \%PAEE from MVPA was associated with lower CVD rates. For example, rates were 24\% (10-35\%) lower for 20 $\mathrm{kJ} / \mathrm{kg} / \mathrm{d}$ PAEE with 20\% from MVPA, 29\% (8-45\%) lower for $30 \mathrm{~kJ} / \mathrm{kg} / \mathrm{d}$ PAEE with $20 \%$ from MVPA, and 49\% (23-66\%) lower for $30 \mathrm{~kJ} / \mathrm{kg} / \mathrm{d}$ with 40\% from MVPA (all compared to 15 $\mathrm{kJ} / \mathrm{kg} / \mathrm{d}$ PAEE with $10 \%$ MVPA). There was considerable uncertainty around levels of PAEE beyond $40 \mathrm{~kJ} / \mathrm{kg} /$ day with a $>20 \%$ fraction of MVPA. Additional adjustment for covariates thought to be on the causal pathway (model 2) slightly attenuated the associations. 
medRxiv preprint doi: https://doi.org/10.1101/2022.02.23.22271386; this version posted February 24, 2022. The copyright holder for this preprint (which was not certified by peer review) is the author/funder, who has granted medRxiv a license to display the preprint in

It is made available under a CC-BY-ND 4.0 International license .

Sex-stratified interaction analyses showed a broadly similar pattern of PAEE and \%PAEE from MVPA associations with CVD rates for both men and women (Figure 3, Figure S4 and Table S2), with the lowest rates of CVD seen with higher levels of both PAEE and \%PAEE from MVPA.

\section{Sensitivity analyses}

The direction and strength of associations for PAEE and \%PAEE from MVPA with CVD rates were consistent when analyses were conducted using acceleration-defined metrics of ENMO and intensity gradient (Figure S5). Excluding participants who had a CVD event within two years of follow-up or with prevalent cancer resulted in similar to slightly attenuated associations (Tables 2 and 3 ). In addition, results did not materially differ in complete-case analyses.

\section{DISCUSSION}

In this large population-based cohort study of middle-aged adults, we found that a higher volume of PAEE, as well as a higher fraction of PAEE accumulated in MVPA, were both associated with lower rates of incident CVD. The role of activity intensity in future CVD risk was apparent in combined volume-and-intensity interaction analyses. Accumulating $20 \%$ rather than $10 \%$ of a total PAEE of $15 \mathrm{~kJ} / \mathrm{kg} / \mathrm{d}$ through MVPA was associated with $17 \%$ lower CVD rate. This is equivalent to the difference between a 12-min stroll and a brisk 7-min walk; both have the same volume, but the higher intensity of the latter is associated with lower CVD rates. Meanwhile, the role of volume was less clear at fixed intensity fractions, with CVD rates not varying significantly across different activity volumes when the fraction accumulated from MVPA was held constant. The greatest differences in CVD rates were seen when comparing the combination of higher volume and intensity with the lowest levels. For example, accumulating $40 \%$ of a total $30 \mathrm{~kJ} / \mathrm{kg} / \mathrm{d}$ PAEE from MVPA was associated with $49 \%$ lower CVD rates compared with accumulating $10 \%$ of a total $15 \mathrm{~kJ} / \mathrm{kg} / \mathrm{d}$ PAEE from MVPA. Although consistent with the latest PA guidelines and supportive of messages that "every move counts" for improving health outcomes $(1,2)$, these findings provide additional evidence that intensity may play an important role in minimising CVD risk, over and above total PA volume.

Our results extend upon previous findings using self-reported (8, 31-35) and accelerometer derived $(7,8,10,13,36)$ measures of PA by examining in more detail the interplay between PA volume and intensity. Using simple, continuous accelerometer-derived metrics of total PAEE and fraction of PAEE from MVPA, we provide a more detailed and integrated perspective on associations with CVD risk, which were previously ambiguous concerning the interactive role of intensity over and above PA volume (13). A notable observation was that 
medRxiv preprint doi: https://doi.org/10.1101/2022.02.23.22271386; this version posted February 24, 2022. The copyright holder for this preprint (which was not certified by peer review) is the author/funder, who has granted medRxiv a license to display the preprint in It is made available under a CC-BY-ND 4.0 International license .

when exposures were combined in interaction analyses, the association of PAEE and CVD risk at a given value of \%PAEE from MVPA was weaker than when PAEE was the only exposure. Comparing these results with those from similar analyses for all-cause mortality (7), this finding suggests that intensity is relatively more important in minimising CVD risk.

We had anticipated stronger evidence of an association with PA intensity for incident CVD; since higher intensities should theoretically provide greater stimuli (e.g. overload, specificity, and/or relative intensity) for physiological adaptation in functions recognized to specifically influence and maintain cardiorespiratory fitness and vascular function (18-21, 37). This is consistent with previous research showing that self-reported walking pace, a measure of habitual movement intensity and function, is a stronger predictor of CVD mortality than other PA or lifestyle-related factors $(38,39)$. In addition, it has previously been noted that cardiorespiratory fitness is a cardiovascular vital sign (40), which has been shown to respond particularly to intensity and less so to volume (41). Therefore, it is possible that the relative importance of intensity observed in this study is mediated by improvements in cardiorespiratory fitness and vascular function.

Although it is important to note the inherent inter-relationships between PA volume and intensity (Figure S3), focusing on increasing MVPA and the intensity of habitual movement, such as walking, regardless of the overall daily volume of PA, could have relevance for CVD prevention or targeting for future interventions. Taken together, the public health message is therefore to increase overall volume of activity and, if possible, do so by incorporating more intense activities. Indeed, for any given activity volume (e.g., walking, or the completion of a set list of manual chores), accumulating this volume at higher intensity (e.g., walking faster, or completing chores more quickly/enthusiastically) would also take up less time, which may be particularly attractive for time-poor individuals or for intervention strategies aimed at freeing up time to increase overall PA levels (19).

A key strength of this study is its large sample size, allowing sufficient variation to investigate interactions across the distributions of PA volume and intensity. In addition, the accelerometer-derived metric of PAEE has a strong validation foundation $(24,25)$ (see Table S1), is easily interpretable, and potentially more applicable to wrist-worn wearable devices for personalised prevention. Although translation of wrist-worn acceleration to energy expenditure does have some limitations, associations with CVD were consistent when analyses were repeated using purely acceleration-based measures of PA volume and intensity (albeit on different exposure scales), providing further confidence in our results. The extensively phenotyped population allowed a comprehensive investigation into possible confounding or mediating influences on the associations between PA volume or intensity with incident CVD; however, residual bias may also have occurred via some unmeasured 
medRxiv preprint doi: https://doi.org/10.1101/2022.02.23.22271386; this version posted February 24, 2022. The copyright holder for this preprint (which was not certified by peer review) is the author/funder, who has granted medRxiv a license to display the preprint in

It is made available under a CC-BY-ND 4.0 International license.

factors and/or included variables measured with substantial error. We performed several additional sensitivity analyses to investigate and help minimise the potential for reverse causality biases (an important limitation of any observation study) but acknowledge that we cannot fully ameliorate this concern.

Further limitations include the single time-point measure of PA, which limits any potential inferences related to within-person changes or variability in PA over time, and the nonconcurrent measurement of covariates and accelerometry. In addition, UK Biobank is not a population-representative cohort (42) and the accelerometer sample may be subject to further selection pressures, which may impact on generalisability. However PA volumes are comparable to national estimates (43) and a previous study showed exposure-outcome associations found in UK Biobank were similar to results in more representative samples (44). Total CVD is a fairly heterogeneous outcome, and we only considered intensity at an absolute level, while intensity relative to maximal capacity may be more critical to driving physiological adaptations $(18,45,46)$. Differences in associations for CVD outcomes relative to all-cause mortality (7) could also be related to variations in follow up time and/or greater exclusions for prevalent disease (47), although further sensitivity analyses did not indicate this to be a major factor. Future pooled research should aim to confirm these findings in other populations, consider including repeated accelerometer PA exposures, and incorporate other biomarkers and disease endpoints (including different CVD sub-types or severity) to shed further light on potential mechanisms. Examination of activity volume and intensity interactions in the context of differing levels of adiposity status would also provide valuable insights (48).

\section{Conclusion}

In this large population-based cohort, we show that both higher volumes of PA, and a greater proportion of that volume accumulated as at least moderate intensity, are associated with lower rates of incident CVD in both men and women. The role of activity intensity, over and above that of total volume, also appears to be particularly relevant for CVD risk. These findings align with current PA recommendations and are supportive of messages that "any amount of PA is better than none, and more is better" (i.e., every move counts). They also support multiple approaches to PA participation, some of which may be more practical or appealing to different individuals. 
medRxiv preprint doi: https://doi.org/10.1101/2022.02.23.22271386; this version posted February 24, 2022. The copyright holder for this preprint (which was not certified by peer review) is the author/funder, who has granted medRxiv a license to display the preprint in It is made available under a CC-BY-ND 4.0 International license .

\section{DECLARATIONS}

\section{Ethics approval and consent to participate}

The UK Biobank study received ethical approval from the Northwest England Research Ethics Committee (reference 16/NW/0274). Participants gave informed consent before participation.

\section{Consent for publication}

Not applicable

\section{Availability of data and materials}

The UK Biobank resource can be accessed by researchers on application. Variables derived for this study will be returned to the UK Biobank for future applicants to request. No additional data are available.

\section{Funding}

Research conducted using the UK Biobank Resource under Application \#33266. TY, AR and parts of the accelerometer data processing were supported by the Lifestyle Theme of the Leicester NHR Leicester Biomedical Research Centre and NIHR Applied Research Collaborations East Midlands (ARC-EM). PCD, TS, SB, and KW were/are supported by the UK Medical Research Council [grant numbers MC_UU_00006/4]. PCD was supported by a National Health and Medical Research Council of Australia research fellowship (\#1142685). SB is supported by the NIHR Biomedical Research Centre in Cambridge (IS-BRC-121520014).

\section{Competing Interests}

The authors had financial support from the funders listed above for the submitted work. The authors declare that they have no competing interests.

\section{Authors' contributions}

PCD, AR, TS, KW, SB, and TY formed the core working group and developed the research question. PCD and TS developed the analysis code, and TS independently replicated the results. PCD ran the final analysis and drafted the manuscript. All authors contributed to the interpretation and revised the manuscript for important intellectual content.

\section{Acknowledgements}

We are grateful to the participants of the UK Biobank Study and those who collected and manage the data. 
medRxiv preprint doi: https://doi.org/10.1101/2022.02.23.22271386; this version posted February 24, 2022. The copyright holder for this preprint (which was not certified by peer review) is the author/funder, who has granted medRxiv a license to display the preprint in perpetuity.

\section{REFERENCES}

1. Bull FC, Al-Ansari SS, Biddle S, Borodulin K, Buman MP, Cardon G, et al. World Health Organization 2020 guidelines on physical activity and sedentary behaviour. British journal of sports medicine. 2020;54(24):1451-62.

2. Piercy KL, Troiano RP, Ballard RM, Carlson SA, Fulton JE, Galuska DA, et al. The Physical Activity Guidelines for Americans. JAMA. 2018;320(19):2020-8.

3. Powell KE, King AC, Buchner DM, Campbell WW, DiPietro L, Erickson KI, et al. The Scientific Foundation for the Physical Activity Guidelines for Americans, 2nd Edition. J Phys Act Health. 2018:1-11.

4. Shephard RJ. Limits to the measurement of habitual physical activity by questionnaires. British journal of sports medicine. 2003;37(3):197-206; discussion

5. Bassett DR, Troiano RP, McClain JJ, Wolff DL. Accelerometer-based physical activity: total volume per day and standardized measures. Med Sci Sports Exerc. 2015;47(4):833-8.

6. Lindsay T, Westgate K, Wijndaele K, Hollidge S, Kerrison N, Forouhi N, et al. Descriptive epidemiology of physical activity energy expenditure in UK adults (The Fenland study). Int J Behav Nutr Phys Act. 2019;16(1):126.

7. Strain T, Wijndaele K, Dempsey PC, Sharp SJ, Pearce M, Jeon J, et al. Wearabledevice-measured physical activity and future health risk. Nat Med. 2020;26(9):1385-91.

8. Saint-Maurice PF, Troiano RP, Berrigan D, Kraus WE, Matthews CE. Volume of Light Versus Moderate-to-Vigorous Physical Activity: Similar Benefits for All-Cause Mortality? Journal of the American Heart Association. 2018;7(7).

9. Matthews CE, Keadle SK, Troiano RP, Kahle L, Koster A, Brychta R, et al. Accelerometer-measured dose-response for physical activity, sedentary time, and mortality in US adults. The American journal of clinical nutrition. 2016.

10. Ekelund U, Tarp J, Steene-Johannessen J, Hansen BH, Jefferis B, Fagerland MW, et al. Dose-response associations between accelerometry measured physical activity and sedentary time and all cause mortality: systematic review and harmonised metaanalysis. BMJ. 2019;366:14570.

11. Jefferis BJ, Parsons TJ, Sartini C, Ash S, Lennon LT, Papacosta O, et al. Objectively measured physical activity, sedentary behaviour and all-cause mortality in older men: does volume of activity matter more than pattern of accumulation? British journal of sports medicine. 2018.

12. LaCroix AZ, Bellettiere J, Rillamas-Sun E, Di C, Evenson KR, Lewis CE, et al. Association of Light Physical Activity Measured by Accelerometry and Incidence of Coronary Heart Disease and Cardiovascular Disease in Older Women. JAMA Netw Open. 2019;2(3):e190419. 
medRxiv preprint doi: https://doi.org/10.1101/2022.02.23.22271386; this version posted February 24, 2022. The copyright holder for this preprint (which was not certified by peer review) is the author/funder, who has granted medRxiv a license to display the preprint in It is made available under a CC-BY-ND 4.0 International license.

13. Ramakrishnan R, Doherty A, Smith-Byrne K, Rahimi K, Bennett D, Woodward M, et al. Accelerometer measured physical activity and the incidence of cardiovascular disease: Evidence from the UK Biobank cohort study. PLoS medicine. 2021;18(1):e1003487.

14. Dempsey PC, Strain T, Khaw KT, Wareham NJ, Brage S, Wijndaele K. Prospective Associations of Accelerometer-Measured Physical Activity and Sedentary Time With Incident Cardiovascular Disease, Cancer, and All-Cause Mortality. Circulation. 2020;141(13):1113-5.

15. Walmsley R, Chan S, Smith-Byrne K, Ramakrishnan R, Woodward M, Rahimi K, et al. Reallocation of time between device-measured movement behaviours and risk of incident cardiovascular disease. British journal of sports medicine. 2021.

16. Rowlands AV, Dawkins NP, Maylor B, Edwardson CL, Fairclough SJ, Davies MJ, et al. Enhancing the value of accelerometer-assessed physical activity: meaningful visual comparisons of data-driven translational accelerometer metrics. Sports medicine - open. 2019;5(1):47.

17. Rowlands AV, Edwardson CL, Davies MJ, Khunti K, Harrington DM, Yates T. Beyond Cut Points: Accelerometer Metrics that Capture the Physical Activity Profile. Med Sci Sports Exerc. 2018;50(6):1323-32.

18. Garber CE, Blissmer B, Deschenes MR, Franklin BA, Lamonte MJ, Lee IM, et al. American College of Sports Medicine position stand. Quantity and quality of exercise for developing and maintaining cardiorespiratory, musculoskeletal, and neuromotor fitness in apparently healthy adults: guidance for prescribing exercise. Med Sci Sports Exerc. 2011;43(7):1334-59.

19. Stamatakis E, Huang BH, Maher C, Thogersen-Ntoumani C, Stathi A, Dempsey PC, et al. Untapping the Health Enhancing Potential of Vigorous Intermittent Lifestyle Physical Activity (VILPA): Rationale, Scoping Review, and a 4-Pillar Research Framework. Sports medicine (Auckland, NZ). 2021;51(1):1-10.

20. Hawley JA, Hargreaves M, Joyner MJ, Zierath JR. Integrative biology of exercise. Cell. 2014;159(4):738-49.

21. Maclnnis MJ, Gibala MJ. Physiological adaptations to interval training and the role of exercise intensity. The Journal of physiology. 2017;595(9):2915-30.

22. Norton K, Norton L, Sadgrove D. Position statement on physical activity and exercise intensity terminology. J Sci Med Sport. 2010;13(5):496-502.

23. Sudlow C, Gallacher J, Allen N, Beral V, Burton P, Danesh J, et al. UK biobank: an open access resource for identifying the causes of a wide range of complex diseases of middle and old age. PLoS medicine. 2015;12(3):e1001779.

24. Doherty A, Jackson D, Hammerla N, Plotz T, Olivier P, Granat MH, et al. Large Scale Population Assessment of Physical Activity Using Wrist Worn Accelerometers: The UK Biobank Study. PLoS One. 2017;12(2):e0169649. 
medRxiv preprint doi: https://doi.org/10.1101/2022.02.23.22271386; this version posted February 24, 2022. The copyright holder for this preprint (which was not certified by peer review) is the author/funder, who has granted medRxiv a license to display the preprint in perpetuity.

25. van Hees VT, Fang Z, Langford J, Assah F, Mohammad A, da Silva IC, et al. Autocalibration of accelerometer data for free-living physical activity assessment using local gravity and temperature: an evaluation on four continents. Journal of applied physiology (Bethesda, Md : 1985). 2014;117(7):738-44.

26. van Hees VT, Gorzelniak L, Dean Leon EC, Eder M, Pias M, Taherian S, et al. Separating movement and gravity components in an acceleration signal and implications for the assessment of human daily physical activity. PLoS One. 2013;8(4):e61691.

27. White T, Westgate K, Wareham NJ, Brage S. Estimation of Physical Activity Energy Expenditure during Free-Living from Wrist Accelerometry in UK Adults. PLoS One. 2016;11(12):e0167472.

28. White T, Westgate K, Hollidge S, Venables M, Olivier P, Wareham N, et al. Estimating energy expenditure from wrist and thigh accelerometry in free-living adults: a doubly labelled water study. International journal of obesity (2005). 2019;43(11):2333-42.

29. Textor J, Hardt J, Knuppel S. DAGitty: a graphical tool for analyzing causal diagrams. Epidemiology (Cambridge, Mass). 2011;22(5):745.

30. White IR, Royston P. Imputing missing covariate values for the Cox model. Statistics in medicine. 2009;28(15):1982-98.

31. Gebel K, Ding D, Chey T, Stamatakis E, Brown WJ, Bauman AE. Effect of Moderate to Vigorous Physical Activity on All-Cause Mortality in Middle-aged and Older Australians. JAMA internal medicine. 2015;175(6):970-7.

32. O'Donovan G, Stamatakis E, Stensel DJ, Hamer M. The Importance of VigorousIntensity Leisure-Time Physical Activity in Reducing Cardiovascular Disease Mortality Risk in the Obese. Mayo Clinic proceedings. 2018;93(8):1096-103.

33. Shiroma EJ, Sesso HD, Moorthy MV, Buring JE, Lee IM. Do moderate-intensity and vigorous-intensity physical activities reduce mortality rates to the same extent? Journal of the American Heart Association. 2014;3(5):e000802.

34. Manson JE, Hu FB, Rich-Edwards JW, Colditz GA, Stampfer MJ, Willett WC, et al. A prospective study of walking as compared with vigorous exercise in the prevention of coronary heart disease in women. The New England journal of medicine. 1999;341(9):650-8.

35. Tanasescu M, Leitzmann MF, Rimm EB, Willett WC, Stampfer MJ, Hu FB. Exercise type and intensity in relation to coronary heart disease in men. Jama. 2002;288(16):19942000.

36. Saint-Maurice PF, Troiano RP, Bassett DR, Jr., Graubard BI, Carlson SA, Shiroma EJ, et al. Association of Daily Step Count and Step Intensity With Mortality Among US Adults. JAMA. 2020;323(12):1151-60.

37. Sabag A, Little JP, Johnson NA. Low-volume high-intensity interval training for cardiometabolic health. The Journal of physiology. 2021;n/a(n/a). 
medRxiv preprint doi: https://doi.org/10.1101/2022.02.23.22271386; this version posted February 24, 2022. The copyright holder for this preprint (which was not certified by peer review) is the author/funder, who has granted medRxiv a license to display the preprint in perpetuity.

38. Argyridou S, Zaccardi F, Davies MJ, Khunti K, Yates T. Walking pace improves allcause and cardiovascular mortality risk prediction: A UK Biobank prognostic study. European journal of preventive cardiology. 2020;27(10):1036-44.

39. Zaccardi F, Franks PW, Dudbridge F, Davies MJ, Khunti K, Yates T. Mortality risk comparing walking pace to handgrip strength and a healthy lifestyle: A UK Biobank study. European journal of preventive cardiology. 2019:2047487319885041.

40. Ross R, Blair SN, Arena R, Church TS, Despres JP, Franklin BA, et al. Importance of Assessing Cardiorespiratory Fitness in Clinical Practice: A Case for Fitness as a Clinical Vital Sign: A Scientific Statement From the American Heart Association. Circulation. 2016;134(24):e653-e99.

41. O'Donovan G, Owen A, Bird SR, Kearney EM, Nevill AM, Jones DW, et al. Changes in cardiorespiratory fitness and coronary heart disease risk factors following 24 wk of moderate- or high-intensity exercise of equal energy cost. Journal of applied physiology (Bethesda, Md : 1985). 2005;98(5):1619-25.

42. Fry A, Littlejohns TJ, Sudlow C, Doherty N, Adamska L, Sprosen T, et al. Comparison of Sociodemographic and Health-Related Characteristics of UK Biobank Participants With Those of the General Population. American Journal of Epidemiology. 2017;186(9):102634.

43. Brage S, Lindsay T, Venables M, Wijndaele K, Westgate K, Collins D, et al. Descriptive epidemiology of energy expenditure in the UK: findings from the National Diet and Nutrition Survey 2008-15. International Journal of Epidemiology. 2020;49(3):1007-21.

44. Batty GD, Gale CR, Kivimaki M, Deary IJ, Bell S. Comparison of risk factor associations in UK Biobank against representative, general population based studies with conventional response rates: prospective cohort study and individual participant metaanalysis. BMJ. 2020;368:m131.

45. Shephard RJ. Absolute versus relative intensity of physical activity in a dose-response context. Med Sci Sports Exerc. 2001;33(6 Suppl):S400-18; discussion S19-20.

46. Jamnick NA, Pettitt RW, Granata C, Pyne DB, Bishop DJ. An Examination and Critique of Current Methods to Determine Exercise Intensity. Sports medicine (Auckland, NZ). 2020;50(10):1729-56.

47. Strain T, Wijndaele K, Sharp SJ, Dempsey PC, Wareham N, Brage S. Impact of followup time and analytical approaches to account for reverse causality on the association between physical activity and health outcomes in UK Biobank. Int J Epidemiol. 2020;49(1):162-72.

48. Lindsay T, Wijndaele K, Westgate K, Dempsey P, Strain T, De Lucia Rolfe E, et al. Joint associations between objectively measured physical activity volume and intensity with body fatness: the Fenland study. International journal of obesity (2005). 2022;46(1):16977. 
Table 1. Descriptive characteristics of the whole sample at baseline, by incident CVD status, and by sex.

\begin{tabular}{|c|c|c|c|c|c|}
\hline Characteristics & $\begin{array}{c}\text { Whole sample } \\
(n=88,412)\end{array}$ & $\begin{array}{l}\begin{array}{l}\text { Non-cases } \\
(n=84,344)\end{array} \\
\end{array}$ & $\begin{array}{c}\text { Cases } \\
(n=4,068)\end{array}$ & $\begin{array}{c}\text { Men } \\
(n=36,903) \\
\end{array}$ & $\begin{array}{c}\text { Women } \\
(n=51,509)\end{array}$ \\
\hline Follow-up time (years), median (IQR) & $6.8(6.2-7.3)$ & $6.8(6.3-7.3)$ & $4.1(2.6-5.5)$ & $6.8(6.2-7.3)$ & $6.8(6.2-7.3)$ \\
\hline Age (years), mean $(S D)$ & $62.0(7.8)$ & $61.8(7.8)$ & $66.3(6.7)$ & $62.5(8.0)$ & $61.7(7.7)$ \\
\hline Sex, n (\%) & $51,509(58.3 \%)$ & $49,805(59.0 \%)$ & $1,704(41.9 \%)$ & - & - \\
\hline White ethnicity, no. (\%) & $85,400(96.9 \%)$ & $81,468(96.9 \%)$ & $3,932(97.1 \%)$ & $35,693(97.1 \%)$ & $49,707(96.8 \%)$ \\
\hline \multicolumn{6}{|l|}{ Highest educational level achieved, n (\%) } \\
\hline No qualification & $6,709(7.6 \%)$ & $6,213(7.4 \%)$ & $496(12.2 \%)$ & $2,854(7.7 \%)$ & $3,855(7.5 \%)$ \\
\hline Any other qualification & $42,083(47.6 \%)$ & $40,093(47.5 \%)$ & $1,990(48.9 \%)$ & $16,807(45.5 \%)$ & $25,276(49.1 \%)$ \\
\hline Degree level or above & $38,978(44.1 \%)$ & $37,441(44.4 \%)$ & $1,537(37.8 \%)$ & $16,974(46.0 \%)$ & $22,004(42.7 \%)$ \\
\hline Townsend indicator of multiple deprivation, median (IQR) & $-2.45(-3.82--0.20)$ & $-2.45(-3.82--0.21)$ & $-2.44(-3.75--0.06)$ & $-2.52(-3.86--0.30)$ & $-2.41(-3.79--0.12)$ \\
\hline In employment, n (\%) & $54,436(61.7 \%)$ & $52,637(62.5 \%)$ & $1,799(44.4 \%)$ & $23,468(63.7 \%)$ & $30,968(60.2 \%)$ \\
\hline \multicolumn{6}{|l|}{ Cigarette smoking, n (\%) } \\
\hline Never & $51,191(57.9 \%)$ & $49,206(58.3 \%)$ & $1,985(48.8 \%)$ & $19,721(53.4 \%)$ & $31,470(61.1 \%)$ \\
\hline Previous & $31,170(35.3 \%)$ & $29,455(34.9 \%)$ & $1,715(42.2 \%)$ & $14,153(38.4 \%)$ & $17,017(33.0 \%)$ \\
\hline Current & $5,833(6.6 \%)$ & $5,484(6.5 \%)$ & $349(8.6 \%)$ & $2,936(8.0 \%)$ & $2,897(5.6 \%)$ \\
\hline \multicolumn{6}{|l|}{ Alcohol consumption, $\mathrm{n}(\%)$} \\
\hline Never or previous & $4,911(5.6 \%)$ & $4,622(5.5 \%)$ & $289(7.1 \%)$ & $1,630(4.4 \%)$ & $3,281(6.4 \%)$ \\
\hline$<$ Twice a week & $40,551(45.9 \%)$ & $38,742(45.9 \%)$ & $1,809(44.5 \%)$ & $14,399(39.0 \%)$ & $26,152(50.8 \%)$ \\
\hline At least three times a week & $42,880(48.5 \%)$ & $40,914(48.5 \%)$ & $1,966(48.3 \%)$ & $20,848(56.5 \%)$ & $22,032(42.8 \%)$ \\
\hline \multicolumn{6}{|l|}{ Added salt intake, $\mathbf{n}(\%)$} \\
\hline Never/rarely & $53,092(60.1 \%)$ & $50,744(60.2 \%)$ & $2,348(57.7 \%)$ & $21,663(58.7 \%)$ & $31,429(61.0 \%)$ \\
\hline Sometimes or more frequent & $24,254(27.4 \%)$ & $23,105(27.4 \%)$ & $1,149(28.2 \%)$ & $10,257(27.8 \%)$ & $13,997(27.2 \%)$ \\
\hline Usually/Always & $11,026(12.5 \%)$ & $10,458(12.4 \%)$ & $568(14.0 \%)$ & $4,965(13.5 \%)$ & $6,061(11.8 \%)$ \\
\hline \multicolumn{6}{|l|}{ Oily fish consumption, $\mathrm{n}(\%)$} \\
\hline More than once a week & $49,642(56.3 \%)$ & $47,249(56.1 \%)$ & $2,393(59.0 \%)$ & $19,972(54.3 \%)$ & $29,670(57.7 \%)$ \\
\hline Fruit and vegetable intake score, median (IQR) & $2.00(1.00-2.00)$ & $2.00(1.00-2.00)$ & $2.00(1.00-2.00)$ & $1.00(1.00-2.00)$ & $2.00(1.00-3.00)$ \\
\hline Weekly frequency of red or processed meat intake, median (IQR) & $0.75(0.50-1.13)$ & $0.75(0.50-1.13)$ & $0.75(0.50-1.25)$ & $1.00(0.63-1.25)$ & $0.63(0.50-1.13)$ \\
\hline \multicolumn{6}{|l|}{ Mean sleep duration, $\mathrm{n}(\%)$} \\
\hline$<7$ hours/day & $19,216(21.7 \%)$ & $18,256(21.6 \%)$ & $960(23.6 \%)$ & $8,222(22.3 \%)$ & 10,994 (21.3\%) \\
\hline
\end{tabular}


7-8 hours/day

$>8$ hours/day

Parental history of cardiovascular disease or cancer, $\mathrm{n}(\%)$

Normal weight $\left(<25 \mathrm{~kg} / \mathrm{m}^{2}\right)$

Overweight $\left(25-30 \mathrm{~kg} / \mathrm{m}^{2}\right)$

Obese $\left(\geq 30 \mathrm{~kg} / \mathrm{m}^{2}\right)$

Current prescription of blood pressure or cholesterol medicine, $\mathrm{n}(\%)$

Diagnosis of diabetes or insulin prescription, $\mathrm{n}(\%)$

Previous diagnosis of cancer, $\mathrm{n}(\%)$

Mobility limitation, $n$ (\%)

\section{Axivity accelerometer ${ }^{a}$}

Valid wear-time, hr/day, median (IQR)

PAEE ( $\mathrm{kJ} / \mathrm{kg} /$ day), mean (SD)

ENMO (mg), mean (SD)

Intensity gradient, mean (SD)

\section{Body mass index, $\mathbf{n}(\%)$}

Valid wear days, median (IQR)

\%PAEE from MVPA, mean (SD)

$\begin{array}{ccccc}63,472(71.8 \%) & 60,702(72.0 \%) & 2,770(68.1 \%) & 26,503(71.8 \%) & 36,969(71.8 \%) \\ 5,496(6.2 \%) & 5,168(6.1 \%) & 328(8.1 \%) & 2,111(5.7 \%) & 3,385(6.6 \%) \\ 63,239(72.5 \%) & 60,133(72.3 \%) & 3,106(77.5 \%) & 25,886(71.1 \%) & 37,353(73.5 \%) \\ & & & & \\ 35,861(40.6 \%) & 34,619(41.0 \%) & 1,242(30.5 \%) & 11,403(30.9 \%) & 24,458(47.5 \%) \\ 36,055(40.8 \%) & 34,276(40.6 \%) & 1,779(43.7 \%) & 18,159(49.2 \%) & 17,896(34.7 \%) \\ 16,330(18.5 \%) & 15,296(18.1 \%) & 1,034(25.4 \%) & 7,265(19.7 \%) & 9,065(17.6 \%) \\ 17,629(20.0 \%) & 16,166(19.2 \%) & 1,463(36.1 \%) & 9,167(24.9 \%) & 8,462(16.5 \%) \\ 2,674(3.0 \%) & 2,379(2.8 \%) & 295(7.3 \%) & 1,551(4.2 \%) & 1,123(2.2 \%) \\ 10,310(11.7 \%) & 9,657(11.5 \%) & 653(16.1 \%) & 3,848(10.4 \%) & 6,462(12.6 \%) \\ 29,364(33.3 \%) & 27,486(32.6 \%) & 1,878(46.2 \%) & 13,150(35.7 \%) & 16,214(31.5 \%)\end{array}$

$\begin{array}{ccccc}6.9(6.7-7.0) & 6.9(6.7-7.0) & 6.9(6.7-7.0) & 6.9(6.7-7.0) & 6.9(6.6-7.0) \\ 24.0(23.6-24.0) & 24.0(23.6-24.0) & 24.0(23.6-24.0) & 24.0(23.8-24.0) & 23.8(23.6-24.0) \\ 41.67(11.37) & 41.84(11.36) & 38.14(11.02) & 40.65(11.56) & 42.40(11.17) \\ 34.67(11.15) & 34.86(11.10) & 30.69(11.33) & 35.93(11.27) & 33.77(10.97) \\ 28.59(8.42) & 28.72(8.42) & 26.01(7.95) & 28.18(8.80) & 28.89(8.12) \\ -2.54(0.19) & -2.54(0.19) & -2.59(0.20) & -2.50(0.20) & -2.57(0.18)\end{array}$

$\mathrm{CVD}=$ cardiovascular disease; MVPA= moderate-to-vigorous physical activity; PAEE= physical activity energy expenditure; ENMO= Euclidian Norm Minus One

Townsend score= a composite area-level measure of deprivation based on unemployment, non-car ownership, non-home ownership, and household overcrowding; a higher score indicates higher deprivation. 

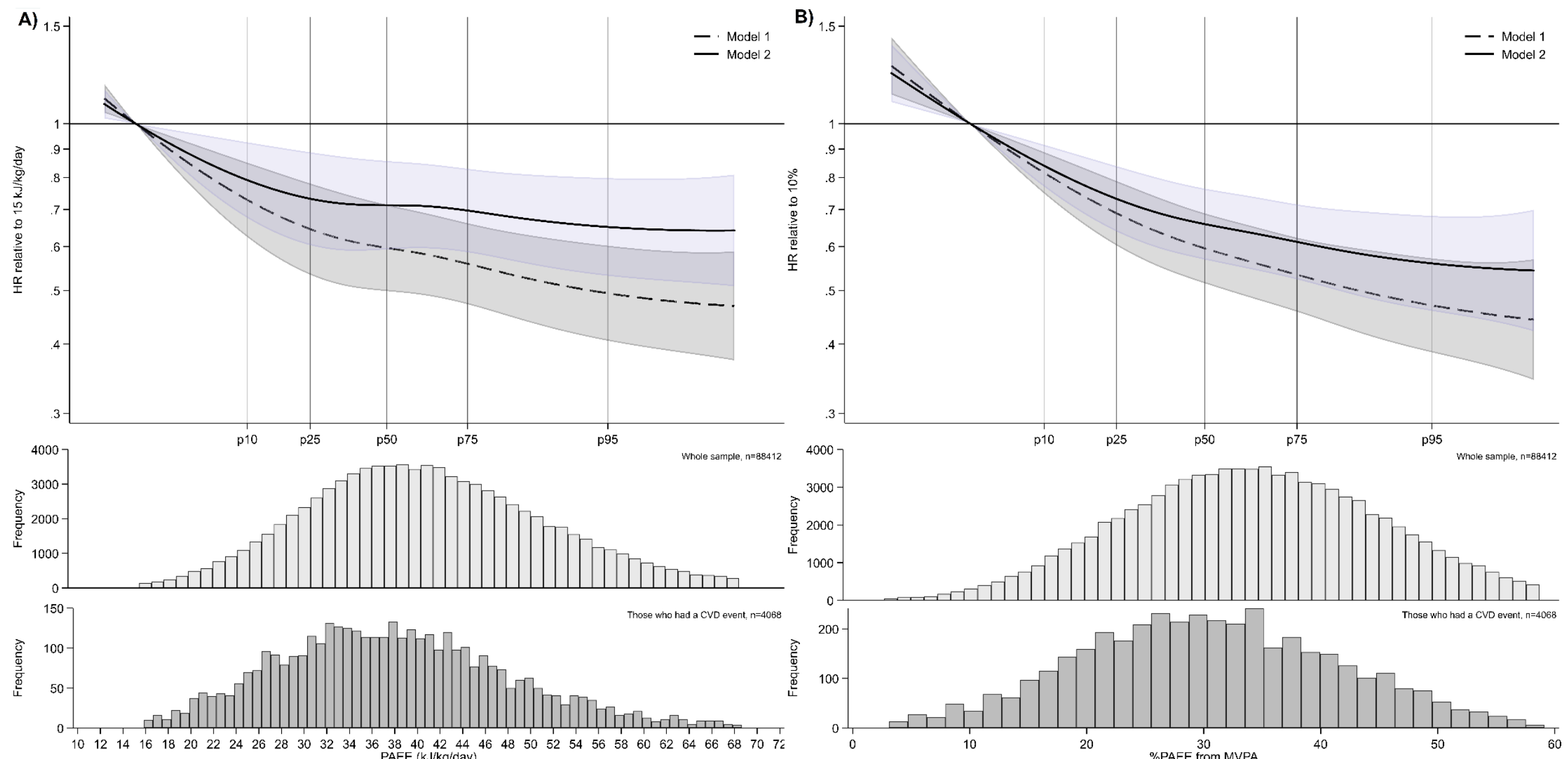

Figure 1. Baseline exposure distribution and adjusted hazard ratios of incident CVD comparing $(A)$ different volumes of PAEE and (B) different fractions of PAEE from MVPA*

* \%PAEE from MVPA models (panel B) are additionally adjusted for PAEE

- Models were fitted using cubic splines ( 3 evenly-spaced knots). Adjusted hazard ratios and histogram data shown for values between the $1^{\text {st }}$ or $99^{\text {th }}$ percentiles of the exposure distribution among those who had a CVD event.

- Model 1 is adjusted for sex (with age as the underlying time scale), ethnicity, education level, employment status, Townsend index of deprivation, season of accelerometer wear, dietary variables, alcohol intake, smoking status, average sleep duration, parental history of cardiovascular disease or cancer), and prevalent cancer.

- Model 2 adjusts for covariates in model 1, with additional adjustment for health-related variables thought to be on the causal pathway (blood pressure or cholesterol medication use, insulin prescription or diagnosed diabetes, body mass index, and mobility limitation).

- Further sensitivity analyses are detailed in Table 2 and Figure S5. 
Table 2. Adjusted hazard ratios for incident CVD by volume of PAEE and different fractions of PAEE from MVPA.

\begin{tabular}{|c|c|c|c|c|c|c|}
\hline \multirow[b]{3}{*}{ PAEE (kJ/kg/day) } & & & & & & \\
\hline & \multicolumn{6}{|c|}{$\begin{array}{c}\text { Incident CVD } \\
\text { f events }=4,068 ; \text { person years }=584,568 \text { ) }\end{array}$} \\
\hline & 15 & 20 & 30 & 40 & 50 & 60 \\
\hline Model 0 & 1 & $0.80(0.73-0.87)$ & $0.57(0.48-0.69)$ & $0.50(0.42-0.59)$ & $0.44(0.37-0.53)$ & $0.41(0.33-0.49)$ \\
\hline Model 1 & 1 & $0.84(0.77-0.92)$ & $0.65(0.54-0.79)$ & $0.59(0.49-0.70)$ & $0.53(0.44-0.63)$ & $0.49(0.40-0.59)$ \\
\hline Model 2 & 1 & $0.88(0.80-0.96)$ & $0.74(0.61-0.89)$ & $0.71(0.60-0.85)$ & $0.67(0.56-0.81)$ & $0.65(0.52-0.80)$ \\
\hline Model 1 excluding CVD event/death $<2 y r$ or prevalent cancer & 1 & $0.82(0.74-0.91)$ & $0.62(0.49-0.77)$ & $0.57(0.46-0.70)$ & $0.54(0.43-0.67)$ & $0.50(0.39-0.64)$ \\
\hline Model 1 complete-case analysis & 1 & $0.85(0.78-0.93)$ & $0.67(0.55-0.81)$ & $0.59(0.50-0.71)$ & $0.54(0.45-0.65)$ & $0.50(0.41-0.61)$ \\
\hline \%PAEE from MVPA* & 10 & 20 & 30 & 40 & 50 & 60 \\
\hline Model 0 & 1 & $0.71(0.63-0.79)$ & $0.56(0.49-0.63)$ & $0.47(0.42-0.53)$ & $0.42(0.36-0.48)$ & $0.39(0.31-0.48)$ \\
\hline Model 1 & 1 & $0.74(0.65-0.83)$ & $0.60(0.52-0.69)$ & $0.52(0.44-0.61)$ & $0.47(0.39-0.57)$ & $0.44(0.34-0.58)$ \\
\hline Model 2 & 1 & $0.77(0.68-0.87)$ & $0.66(0.57-0.77)$ & $0.60(0.51-0.71)$ & $0.56(0.46-0.68)$ & $0.54(0.41-0.71)$ \\
\hline Model 1 excluding CVD event/death $<2 y r$ or prevalent cancer & 1 & $0.78(0.68-0.90)$ & $0.64(0.54-0.77)$ & $0.59(0.49-0.72)$ & $0.56(0.44-0.71)$ & $0.50(0.36-0.68)$ \\
\hline Model 1 complete-case analysis & 1 & $0.74(0.65-0.83)$ & $0.60(0.52-0.70)$ & $0.53(0.45-0.62)$ & $0.48(0.39-0.58)$ & $0.45(0.34-0.59)$ \\
\hline
\end{tabular}

Note: Model 1b $(n=77,606$, no. of events=2,919); Model 1c $(n=85,451$, no. of events=3,891).

* \%PAEE from MVPA models are additionally adjusted for PAEE. Models 1 and 2 are displayed on Figure 1.

- Model 0 is adjusted for sex (with age as the underlying time scale) only.

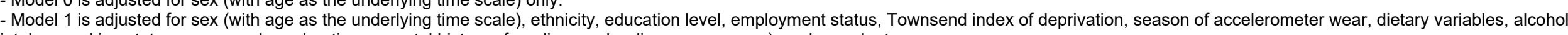
intake, smoking status, average sleep duration, parental history of cardiovascular disease or cancer), and prevalent cancer.

- Model 2 adjusts for covariates in model 1, with additional adjustment for health-related variables thought to be on the causal pathway (blood pressure or cholesterol medication use, insulin prescription or diagnosed diabetes, body mass index, and mobility limitation). 

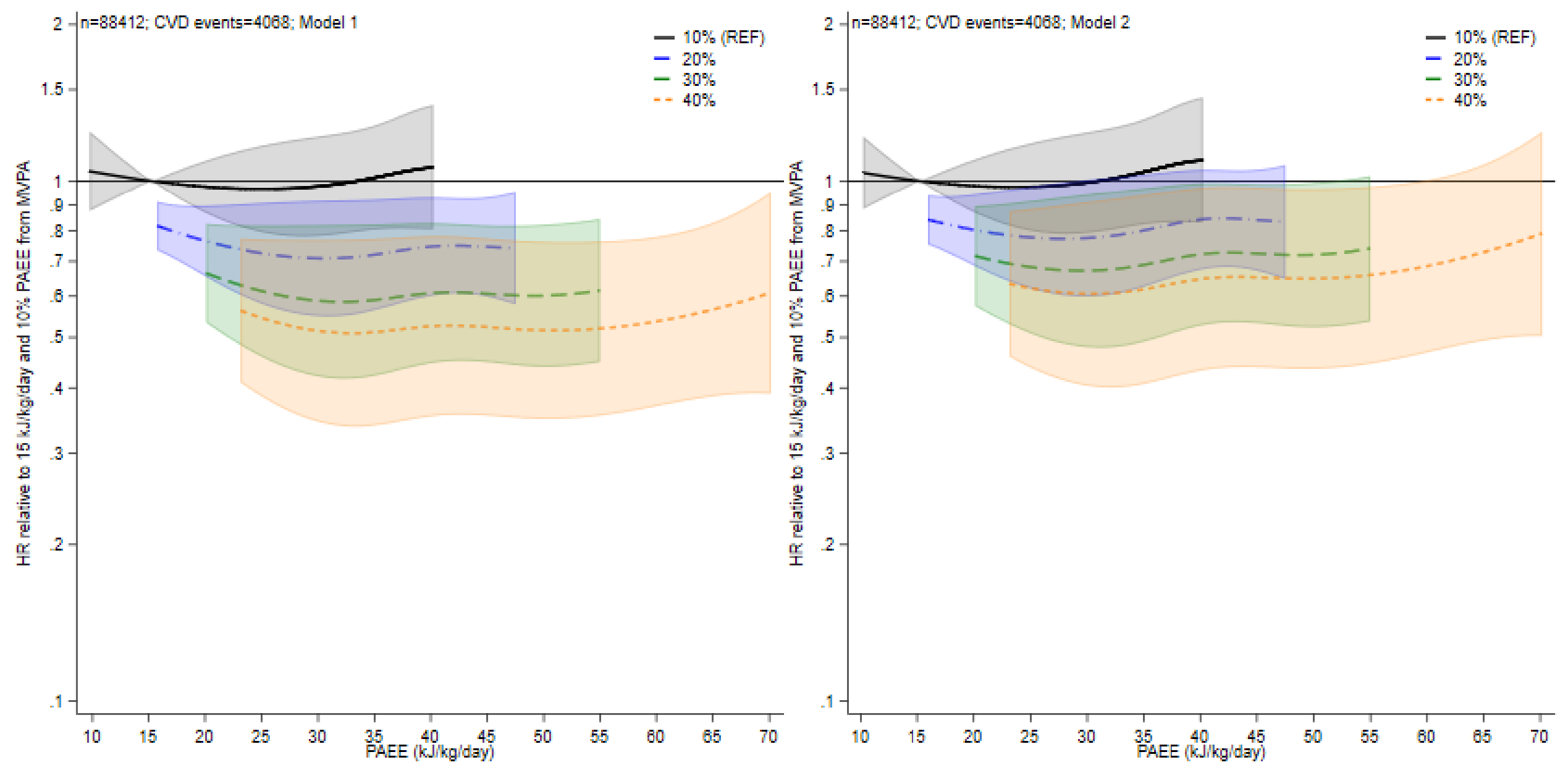

Figure 2. Associations of volume of PAEE and the \%PAEE from MVPA with incident CVD.

- All hazard ratios are relative to a PAEE of $15 \mathrm{~kJ} / \mathrm{kg} /$ day and $10 \%$ fraction from MVPA (i.e. hazard ratio, 1).

- Moving right along each line reflects the hazard ratio for a higher PAEE volume but a constant \%PAEE from MVPA. A comparison between lines at a given point on the X-axis therefore reflects the hazard ratio for an increase in intensity but at a constant PAEE. Hazard ratios $(95 \% \mathrm{Cl})$ are shown for values between the $1^{\text {st }}$ or $99^{\text {th }}$ percentiles of the PAEE distribution among those who had a CVD event.

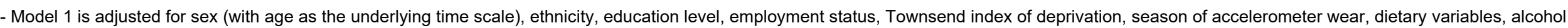
intake, smoking status, average sleep duration, parental history of cardiovascular disease or cancer), and prevalent cancer.

- Model 2 adjusts for covariates in model 1, with additional adjustment for health-related variables thought to be on the causal pathway (blood pressure or cholesterol medication use, insulin prescription or diagnosed diabetes, body mass index, and mobility limitation).

- Further details are shown in Table 3. 
medRxiv preprint doi: https://doi.org/10.1101/2022.02.23.22271386; this version posted February 24, 2022. The copyright holder for this preprint (which was not certified by peer review) is the author/funder, who has granted medRxiv a license to display the preprint in It is made available under a CC-BY-ND 4.0 International license .

Table 3. Adjusted hazard ratios of incident CVD for different values of PAEE and the fraction of PAEE from MVPA.

\begin{tabular}{|c|c|c|c|c|c|}
\hline & & & & & \\
\hline & & Model 1 & Model 2 & $\begin{array}{l}\text { Model } 1 \text { excluding } \\
\text { CVD event/death } \\
<2 \text { yr or prevalent } \\
\text { cancer) }\end{array}$ & $\begin{array}{l}\text { Model } 1 \text { complete- } \\
\text { case analysis }\end{array}$ \\
\hline \multicolumn{2}{|l|}{$\mathrm{n}$} & \multicolumn{2}{|c|}{88412} & 77606 & 85451 \\
\hline \multicolumn{2}{|l|}{ Person-years } & \multicolumn{2}{|c|}{584568} & 516559 & 565068 \\
\hline \multicolumn{2}{|l|}{ CVD events } & \multicolumn{2}{|c|}{4068} & 2919 & 3891 \\
\hline $\begin{array}{l}\text { PAEE } \\
\text { (kJ/kg/day) }\end{array}$ & $\begin{array}{l}\% \text { PAEE } \\
\text { from MVPA }\end{array}$ & & & & \\
\hline \multirow[t]{4}{*}{15} & 10 & 1 (REF) & 1 (REF) & 1 (REF) & 1 (REF) \\
\hline & 20 & $0.83(0.74-0.92)$ & $0.85(0.76-0.95)$ & $0.92(0.81-1.05)$ & $0.81(0.72-0.90)$ \\
\hline & 30 & N/A & $\mathrm{N} / \mathrm{A}$ & $\mathrm{N} / \mathrm{A}$ & $\mathrm{N} / \mathrm{A}$ \\
\hline & 40 & $\mathrm{~N} / \mathrm{A}$ & $\mathrm{N} / \mathrm{A}$ & $\mathrm{N} / \mathrm{A}$ & $\mathrm{N} / \mathrm{A}$ \\
\hline \multirow[t]{4}{*}{20} & 10 & $0.97(0.86-1.10)$ & $0.98(0.86-1.11)$ & $0.93(0.81-1.08)$ & $0.98(0.87-1.12)$ \\
\hline & 20 & $0.76(0.65-0.90)$ & $0.80(0.68-0.95)$ & $0.80(0.66-0.96)$ & $0.76(0.65-0.90)$ \\
\hline & 30 & $0.66(0.53-0.83)$ & $0.72(0.57-0.90)$ & $0.73(0.56-0.95)$ & $0.66(0.52-0.82)$ \\
\hline & 40 & $\mathrm{~N} / \mathrm{A}$ & $\mathrm{N} / \mathrm{A}$ & $\mathrm{N} / \mathrm{A}$ & $\mathrm{N} / \mathrm{A}$ \\
\hline \multirow[t]{4}{*}{30} & 10 & $0.98(0.78-1.22)$ & $0.99(0.79-1.25)$ & $0.87(0.65-1.16)$ & $0.99(0.78-1.25)$ \\
\hline & 20 & $0.71(0.55-0.92)$ & $0.78(0.60-1.01)$ & $0.67(0.49-0.91)$ & $0.72(0.55-0.94)$ \\
\hline & 30 & $0.59(0.42-0.82)$ & $0.67(0.48-0.95)$ & $0.57(0.38-0.86)$ & $0.60(0.42-0.85)$ \\
\hline & 40 & $0.51(0.34-0.77)$ & $0.61(0.40-0.92)$ & $0.51(0.31-0.84)$ & $0.52(0.34-0.80)$ \\
\hline \multirow[t]{4}{*}{40} & 10 & $1.06(0.81-1.40)$ & $1.09(0.83-1.45)$ & $0.93(0.66-1.30)$ & $1.05(0.79-1.39)$ \\
\hline & 20 & $0.75(0.60-0.93)$ & $0.84(0.67-1.06)$ & $0.70(0.54-0.91)$ & $0.75(0.59-0.94)$ \\
\hline & 30 & $0.61(0.44-0.83)$ & $0.72(0.52-0.99)$ & $0.59(0.41-0.87)$ & $0.61(0.44-0.85)$ \\
\hline & 40 & $0.52(0.35-0.79)$ & $0.65(0.43-0.97)$ & $0.53(0.32-0.86)$ & $0.53(0.35-0.81)$ \\
\hline \multirow[t]{4}{*}{50} & 10 & N/A & $\mathrm{N} / \mathrm{A}$ & $\mathrm{N} / \mathrm{A}$ & $\mathrm{N} / \mathrm{A}$ \\
\hline & 20 & $\mathrm{~N} / \mathrm{A}$ & $\mathrm{N} / \mathrm{A}$ & $\mathrm{N} / \mathrm{A}$ & $\mathrm{N} / \mathrm{A}$ \\
\hline & 30 & $0.60(0.44-0.83)$ & $0.72(0.52-1.00)$ & $0.62(0.42-0.90)$ & $0.60(0.43-0.84)$ \\
\hline & 40 & $0.52(0.35-0.77)$ & $0.65(0.43-0.97)$ & $0.54(0.33-0.87)$ & $0.53(0.35-0.79)$ \\
\hline \multirow[t]{4}{*}{60} & 10 & $\mathrm{~N} / \mathrm{A}$ & $\mathrm{N} / \mathrm{A}$ & $\mathrm{N} / \mathrm{A}$ & $\mathrm{N} / \mathrm{A}$ \\
\hline & 20 & N/A & $\mathrm{N} / \mathrm{A}$ & $\mathrm{N} / \mathrm{A}$ & $\mathrm{N} / \mathrm{A}$ \\
\hline & 30 & $\mathrm{~N} / \mathrm{A}$ & $\mathrm{N} / \mathrm{A}$ & $\mathrm{N} / \mathrm{A}$ & $\mathrm{N} / \mathrm{A}$ \\
\hline & 40 & $0.54(0.37-0.78)$ & $0.68(0.46-1.01)$ & $0.56(0.36-0.89)$ & $0.54(0.36-0.80)$ \\
\hline
\end{tabular}

- N/A indicates the specific combination of exposures not between the $1^{\text {st }}$ and $99^{\text {th }}$ percentiles of the PAEE distribution among those who had a CVD event for that \%PAEE from MVPA.

- All hazard ratios are relative to a PAEE of $15 \mathrm{~kJ} / \mathrm{kg} /$ day $\mathrm{mg}$ and a \%PAEE from MVPA of $10 \%$. Models 1 and 2 are displayed on Figure 2.

- Model 1 is adjusted for sex (with age as the underlying time scale), ethnicity, education level, employment status, Townsend index of deprivation, season of accelerometer wear, dietary variables, alcohol intake, smoking status, average sleep duration, parental history of cardiovascular disease or cancer), and prevalent cancer.

- Model 2 adjusts for covariates in model 1, with additional adjustment for health-related variables thought to be on the causal pathway (blood pressure or cholesterol medication use, insulin prescription or diagnosed diabetes, body mass index, and mobility limitation). 

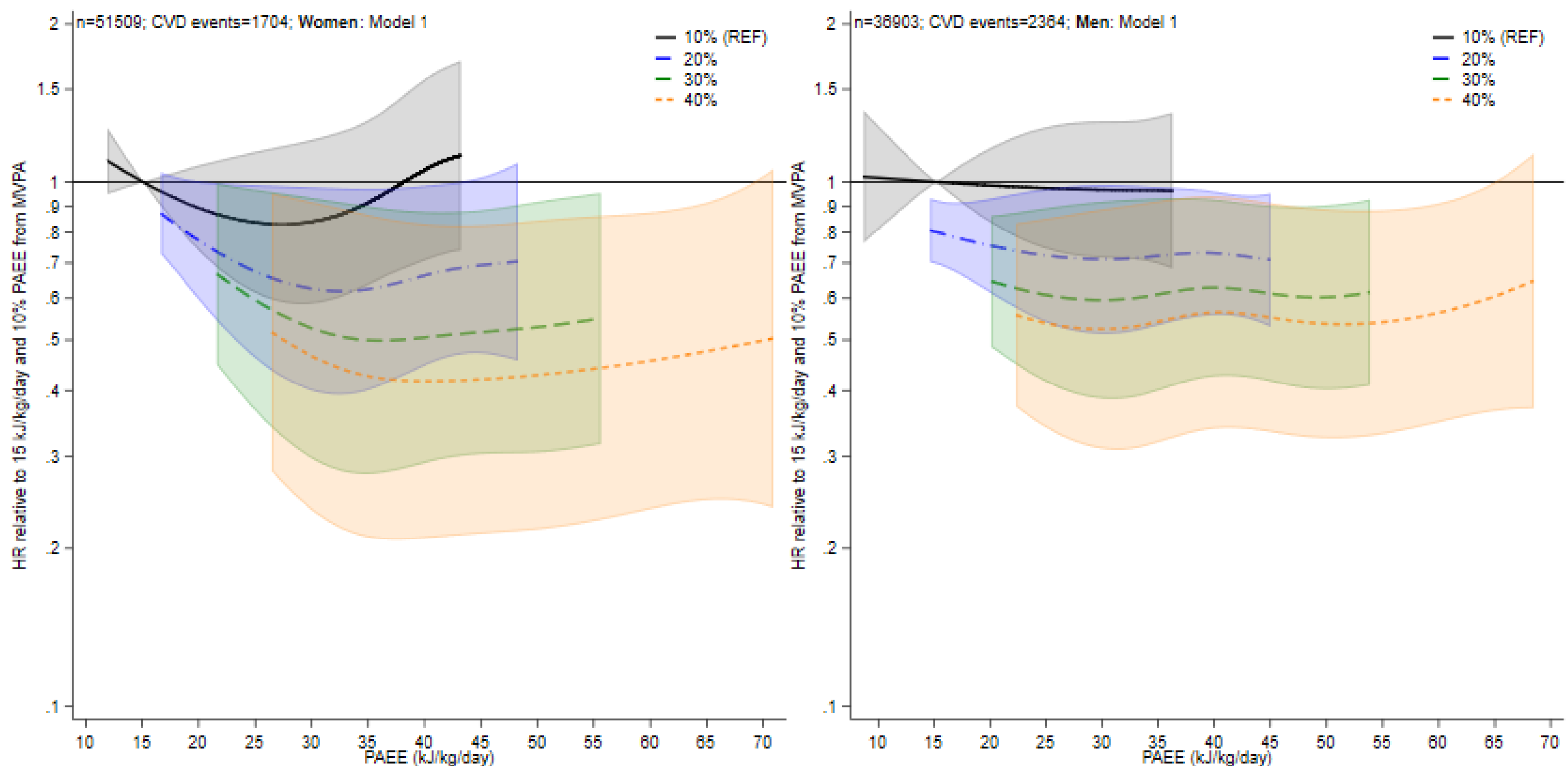

Figure 3. Associations of volume of PAEE the \%PAEE from MVPA with incident CVD (model 1), by sex.

- All hazard ratios are relative to a PAEE of $15 \mathrm{~kJ} / \mathrm{kg} /$ day and $10 \%$ fraction from MVPA. Moving right along each line reflects the hazard ratio for a higher PAEE volume but a constant \%PAEE from MVPA. A comparison between lines at a given point on the $\mathrm{x}$-axis reflects the hazard ratio for an increase in intensity, but a constant PAEE. Hazard ratios shown for values between the $1^{\text {st }}$ or $99^{\text {th }}$ percentiles of the PAEE distribution among those who had a CVD event.

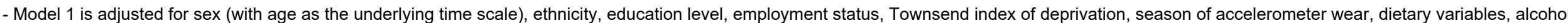
intake, smoking status, average sleep duration, parental history of cardiovascular disease or cancer), and prevalent cancer.

- Figure S4 displays results for model 2. Further details are also shown in Table S2. 